\title{
The immediate effect of incorporating short-term slow abdominal respiration into an exercise program on balance and the autonomic nervous system
}

\author{
Jaein Han ${ }^{a}$, Yoona Chae ${ }^{b}$ Na-Kyung Lee ${ }^{c}$ \\ ${ }^{a}$ Department of Children and Adolescent Rehabilitation, Seoul Rehabilitation Hospital, Seoul, Republic of Korea \\ ${ }^{\mathrm{b}}$ Department of Orthopedics, Musculoskeletal-Rehabilitation Clinic, Seoul, Republic of Korea \\ ${ }^{\mathrm{c} D}$ Department of Physical Therapy, College of Medical Science, Konyang University, Daejeon, Republic of Korea
}

Objective: The purpose of this study was to examine the possible effects of incorporating short-term slow-abdominal respiration (SAR) into an exercise program, on balance and the cardiac-related autonomic nervous system (ANS).

Design: Cross-over repeated measures design.

Methods: Fifteen young and healthy adults were randomly assigned into two groups (7 in the C-R group, 8 in the R-C group), each of which carried out both control sequence $(\mathrm{C})$ and respiration-experiment sequence $(\mathrm{R})$ in the inverse order. In the $\mathrm{C}$ sequence, the subjects performed passive exercises and a general exercise program (P-GEP). In the R sequence, the subjects received a short-term SAR training session and then performed the respiration incorporated general exercises program (R-RGEP). Before and after both $\mathrm{C}$ and $\mathrm{R}$ sequences, the length and the area of the displacement of the center of pressure (COP) and heart rate variability parameters were measured.

Results: The total length of the COP displacement in the left single-leg-standing condition showed a significantly greater reduction after R-RGEP in the respiration-experiment sequence than after the P-GEP in the control sequence $(p<0.05)$. The mean heart rate was significantly reduced only after R-RGEP in the respiration-experiment sequence $(p<0.05)$

Conclusions: The slow-abdominal-respiration, trained in a simple manner and integrated into the exercise program in a single session, showed partially positive immediate effects on balance stabilization. The decrease in heart rate indicated possible involvement of the parasympathetic ANS activation in the stability, although it is not enough to decide whether it is purely due to the controlled respiration.

Key Words: Autonomic nervous system, Postural balance, Respiration

\section{Introduction}

The effects of respiration exercise have been continuously studied, and the researchers have found various therapeutic benefits it can produce. Breathing exercises can induce many bio-psychological effects such as improvement of attention, and reduction of stress, depression, and anxiety [1-4]. It also brings a range of positive effects on the physical aspects of healing in various areas, including car- diopulmonary, musculoskeletal, and pain management [5-8].

From the ancient times to the current history, many types of respiratory techniques have been practiced, and various methods of breathing have been presented in the previous studies. Slow breathing consists of longer inspiration and expiration, for example, 4 seconds of inspiration and 6 seconds of expiration [5]. In diaphragmatic breathing, a person puts the hands on the abdomen and inhales through the nose by expanding the abdomen, suspends the breath at the end of

Received: 5 November, 2019 Revised: 10 December, 2019 Accepted: 12 December, 2019

Corresponding author: Na-Kyung Lee (ORCID https://orcid.org/0000-0003-3872-7945)

Department of Physical Therapy, College of Medical Science, Konyang University, 158 Gwanjeodong-ro, Seo-gu, Daejeon 35365, Republic of Korea Tel: 82-42-600-8458 Fax: 82-42-600-8308 E-mail: wmcg_nkl@konyang.ac.kr

(c) This is an Open-Access article distributed under the terms of the Creative Commons Attribution Non-Commercial License (http://creativecommons.org/licenses/ by-nc/4.0) which permits unrestricted non-commercial use, distribution, and reproduction in any medium, provided the original work is properly cited.

Copyright (๑) 2019 Korean Academy of Physical Therapy Rehabilitation Science 
inhalation, and then exhales through the mouth as the abdomen expands [9]. Abdominal breathing had been commonly referred to be the same or a similar respiratory technique used as diaphragmatic breathing, but sometimes it had covered a more general or less specific type of breathing and did not necessarily include mouth-exhalation, breath-suspension, or hand- placement on the abdomen [10]. Mindful breathing focuses on gentle awareness of natural respiration [11]. The concepts and terminologies about these breathing methods were, however, often overlapped or mixed.

One of the widely accepted and used applications of respiratory exercises used in pulmonary rehabilitation is diaphragmatic breathing. Diaphragmatic breathing increases pulmonary functions such as forced vital capacity [12] and forced expiratory volume [13], activated respiratory muscles, and improved dyspnea [1,13]. In healthy subjects, ventilatory efficiency has improved through diaphragmatic breathing [14]. Another area where breathing exercise is actively applied is lumbar stabilization. Diaphragmatic breathing exercises have been known to facilitate activation of the core muscles including the transversus abdominis and pelvic floor muscles, which are key contributors to the stabilization of lumbar posture [15]. Abdominal-bracing, that is, co-activation of abdominal muscles and the diaphragm, increases intra-abdominal pressure, and this supports proper lumbar alignment [16].

Although breathing exercises have been proved to increase lumbar stability and contribute to posture by promoting alignment as described above, it's effect on balance or postural stability has not been much investigated so far. Maintaining balance during normal or therapeutic activities is essential for a person to perform the movements effectively [17-19]. It is also critical to prevent falls and possible injuries from the fall [20], especially under clinical settings where patients are more vulnerable to falls. A modality that could improve balance instantly when incorporated into the activities, without additionally exerting much time or endeavor over the originally intended program, would provide more stability and safety to perform the activities. The purpose of this study was to preliminarily examine if breathing exercises can bring such an immediate effect on balance when incorporated into a general exercise program (GEP).

In addition, breathing exercises have found to influence the autonomic nervous system (ANS) reaction by increasing parasympathetic or sympathetic modulation [21]. In turn, the ANS modulation was indicated to be possibly involved in postural stability from a recent study where the different levels of a certain hormone-marker of the sympathetic nervous system were shown to accompany with different types of exercise performance and different levels of balance [22]. We postulated that the effect of respiration exercise on the ANS could possibly play a role in balance, and investigated a possible change in the ANS reaction as well.

As a breathing method to be used in this study, rather than taking a single specific method among the previously known ones, we tailored some of them into an adapted method reflecting the key features (slow, using abdomen, cognitive or mindful) and called it 'slow abdominal respiration (SAR)'.

\section{Methods}

\section{Subject}

The subjects were recruited among healthy young adults. A total of 15 subjects ( 2 man, 13 woman) voluntarily participated in the study after informed consent was obtained (Table 1). Anyone who had cardiac diseases or musculoskeletal disorders in their ankles or feet were excluded. This study followed the ethical standards of the Declaration of Helsinki (1975. Revised 1983) and was performed under approval by the Institutional Review Board of Konyang University (IRB No. 2017-078).

\section{Exercise sessions}

\section{The slow-abdominal respiration}

The key features of multiple breathing methods, such as slow breathing, diaphragmatic breathing, abdominal breathing, and mindful breathing [5,9-11] were selected to compose the SAR and were modified in order to fit for the subjects and the environment in this study so that the subjects could learn and apply the respiration techniques easily in a short period of time.

The instructions given to a subject in the procedures of the SAR training were as below.

1. "Sit up straight in a comfort posture." (or "Lie down on

Table 1. General characteristics of the subjects

$(\mathrm{N}=15)$

\begin{tabular}{lc}
\hline \multicolumn{1}{c}{ Item } & Subject \\
\hline Age $(\mathrm{y})$ & $19.73(0.92)$ \\
Gender (man/woman) & $2 / 13$ \\
Height $(\mathrm{cm})$ & $163.00(7.56)$ \\
Weight $(\mathrm{kg})$ & $55.28(7.23)$ \\
Body mass index $\left(\mathrm{kg} / \mathrm{m}^{2}\right)$ & $20.76(2.17)$ \\
\hline
\end{tabular}

Values are presented as mean (SD) or number only. 
your back in a comfort posture.")

2. "Put your hands on the abdomen."

3. "Breathe in with your nose, slowly pushing the abdomen forward, and breathe out with the nose, pushing the abdomen inward."

4. "Breathe in for 3 seconds, and breathe out for 4 seconds." (approximately 8-9 breaths for 1 minutes)

5. "While breathing, gently put your attention on the abdomen under the hands, and then feel the movements of the abdomen."

6. "One, two, three" (while breathing in), "One, two, three, four" (while breathing out) (The instructor counts one, two, three, $\cdots$, verbally with sound to pace the subject's respiration to be slow.)

\section{Passive exercises and a series of general exercises}

The control sequence (C) was composed of passive exercises and a series of general exercises (P-GEP). That is, the subject performed passive exercises first for 6 minutes (3 minutes in sitting and 3 minutes at supine) moved by a researcher, in order to set the length of a session as same as The SAR-incorporated general exercises (R-RGEP). Then, the subject performed the GEP.

The GEP was composed of generally and frequently utilized exercise movements in many rehabilitative clinical settings. The exercises started with bridging exercises in supine for 2 sets of 10 times and hip flexion with resistive band performed in supine with each leg 10 times. In sitting, knee extension with a weight on the ankle was performed for each leg for 2 sets of 10 times. In standing, shoulder abduction with resistive band as well as shoulder internal/external rotation with resistive band was performed for 2 sets of 10 times, right/left single-leg standing for 30 seconds, and 3 minutes of walking in place were performed in order. During the GEP, the subjects were instructed to breathe naturally.

\section{The SAR-incorporated general exercises}

In the experiment sequence (R), R-RGEP was carried out. First, respiration training with the SAR method was carried out for 6 minutes ( 3 minutes in sitting and 3 minutes in supine). As the respiration training session ended, the subject executed RGEP (the respiration [SAR]-incorporated GEP), which consisted of the same exercise components as GEP but it was performed together with the SAR without hand placement on the abdomen. Before the RGEP began, subjects were instructed to breathe with the just trained SAR method while they perform the exercises until the end of the session.

\section{Procedure}

The study adopted a cross-over design. The 15 subjects were divided into two groups of 7 and 8 people and were randomly assigned to either the C-R or R-C groups using computer-generated numbers. The two groups went through both control sequence (C) and respiration-experiment sequence (R), but the order of performing the sequences was opposite. As described above, the $\mathrm{C}$ sequence was made of $\mathrm{P}-\mathrm{GEP}$ in which a subject performed the passive exercises, making a session length as same as in the R sequence, and the GEP and the $\mathrm{R}$ sequence was composed of R-RGEP in which the SAR training was performed first and then was incorporated into the GEP to perform the RGEP.

The subjects in the C-R group executed the $\mathrm{C}$ sequence first, then after 10-11 days of the wash-out period has passed to remove the transfer effect, they executed the $\mathrm{R}$ sequence. The R-C group performed the R sequence first, then had $10-11$ days of the wash-out period $[23,24]$, and went through the $\mathrm{C}$ sequence (Figure 1).

Before and immediately after $\mathrm{C}$ or $\mathrm{R}$ sequence, the degree of balance was measured by the Pedoscan, and the heart rate variability (HRV) as an indicator of the ANS's reaction was

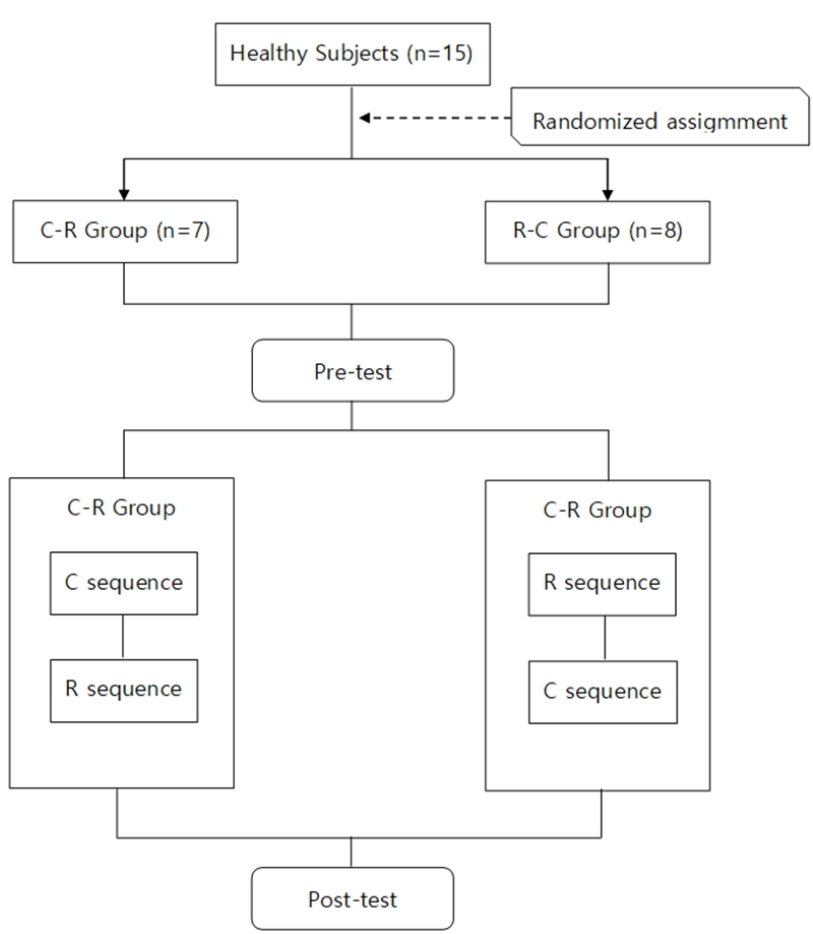

Figure 1. Flowchart of the study design and procedure. C: control, R: respiration. 

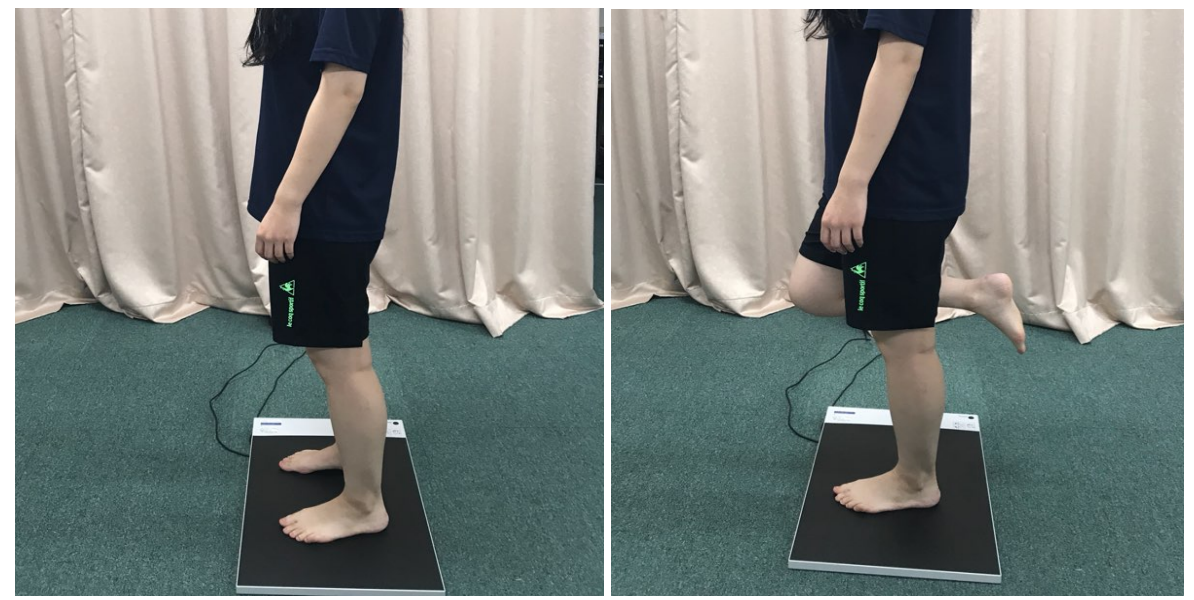

Figure 2. Measurement of the center of pressure displacement using Pedoscan.

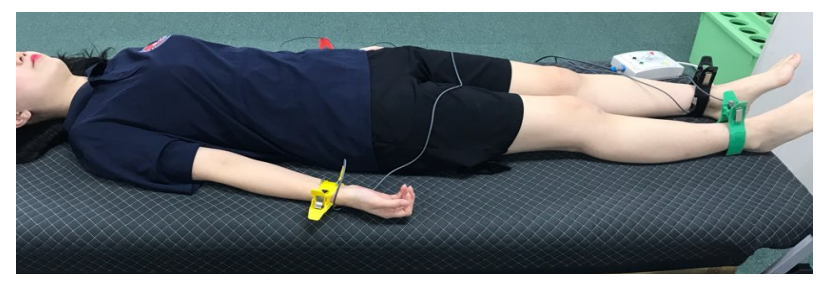

Figure 3. Measurement of heart rate variability.

measured by QECG-3 (LXC3203, LAXTHA Inc., Daejon, Korea).

\section{Instruments and measurements}

\section{Center of pressure displacement}

The Pedoscan (RSscan, Diers, Germany) can locate the center of pressure (COP) of the foot while standing and records the trace or displacement of the COP as the COP moves with the sway of the foot. The Pedoscan then calculates the length of the trace of the COP and the area of the ellipse that the shape of the whole COP trace makes with its short and long axes. The sampling rate was set as $100 \mathrm{~Hz}$.

The force plate $(1.0 \mathrm{~m} \times 4.0 \mathrm{~m})$ measuring the COP was placed on a level surface. The subject stood in a natural standing posture with feet at should-width apart (Figure 2). The subjects were instructed to look at the wall with their eyes horizontally forward.

The parameters were measures in two modes: bilateral stance and unilateral stance. First, the subject remained in standing position for 1 minute on both feet. The measurements were performed three times with a one minute-rest period in between. Next, the remained stayed in single-leg standing for 10 seconds. Three measurements were made for each foot with a thirty-second rest period in between.

\section{Heart rate variability}

To record changes in the ANS, HRV was measured by analyzing the electrocardiogram with the QECG-3. The four electrodes were attached on both wrists and ankles. Activities such as eating, drinking, and smoking that could affect the heart rate (HR) were prohibited 2 hours before the measurement. The subject was in a comfortable supine position on the table during the measurement, which was $5 \mathrm{mi}-$ nutes in duration (Figure 3).

The TeleScan software (LAXTHA Inc.) analyzed the electrocardiogram data into mean HR, standard deviation of normal-beat to normal-beat interval (SDNN), low frequency (LF: 0.04-0.15 Hz), high frequency (HF: 0.15-0.4 Hz), and the $\mathrm{LF} / \mathrm{HF}$ ratio.

\section{Statistical analysis}

The data was statistically analyzed using PASW Statistics for Windows, Version 18.0 (SPSS Inc., Chicago, IL, USA). The paired-t test was used to compare the pre-post effects, and to compare between the control and the experiment sequences (to compare the pre-measurements with the postmeasurements of each $\mathrm{C}$ or $\mathrm{R}$ sequences, and to compare the differences between the pre- and the post-measurements of $\mathrm{C}$ sequence with those of $\mathrm{R}$ sequence) [23]. Statistical significance was set as 0.05 .

\section{Results}

The post-measurement of the COP trace length during left single-leg-standing was significantly decreased than the pre-measurement (Table 2, $p<0.05$ ). There was significant difference between the $\mathrm{C}$ and the $\mathrm{R}$ sequences in the length of the COP displacement during left single-leg-standing; It 
Table 2. Comparison between pre- and post- measurements for COP change during static standing

$(\mathrm{N}=15)$

\begin{tabular}{|c|c|c|c|c|}
\hline Standing leg(s) & COP variable & Pre & Post & $\mathrm{t}(p)$ \\
\hline \multirow[t]{6}{*}{ Bilateral } & Area $\left(\mathrm{mm}^{2}\right)^{\mathrm{a}}$ & & & \\
\hline & Control & $189.98(138.04)$ & $190.65(125.25)$ & $-0.047(0.963)$ \\
\hline & Respiration & $150.20(49.82)$ & $188.03(115.64)$ & $-1.600(0.132)$ \\
\hline & Length $(\mathrm{mm})^{\mathrm{b}}$ & & & \\
\hline & Control & $1619.66(180.84)$ & $1576.62(139.11)$ & $1.414(0.179)$ \\
\hline & Respiration & $1563.87(206.32)$ & $1553.68(219.38)$ & $0.617(0.547)$ \\
\hline \multirow[t]{6}{*}{ Right } & Area $\left(\mathrm{mm}^{2}\right)$ & & & \\
\hline & Control & $341.74(141.90)$ & $372.37(105.82)$ & $-0.857(0.406)$ \\
\hline & Respiration & $328.39(84.03)$ & 354.18 (112.79) & $-0.914(0.376)$ \\
\hline & Length (mm) & & & \\
\hline & Control & $317.97(59.24)$ & $309.88(63.91)$ & $0.752(0.464)$ \\
\hline & Respiration & $316.40(66.45)$ & $300.60(54.72)$ & $1.402(0.183)$ \\
\hline \multirow[t]{6}{*}{ Left } & Area $\left(\mathrm{mm}^{2}\right)$ & & & \\
\hline & Control & $309.33(104.74)$ & $342.37(82.35)$ & $-1.562(0.141)$ \\
\hline & Respiration & $334.73(125.30)$ & $330.18(108.31)$ & $0.173(0.865)$ \\
\hline & Length (mm) & & & \\
\hline & Control & $290.73(57.10)$ & $297.80(52.63)$ & $-0.835(0.418)$ \\
\hline & Respiration & $297.31(49.46)$ & $279.00(46.79)$ & $2.167(0.048)^{*}$ \\
\hline
\end{tabular}

Values are presented as mean (SD).

COP: center of pressure.

${ }^{\mathrm{a}}$ Area of the eclipse drawn with the short and long axes of the shape of the COP trace. ${ }^{\mathrm{b}}$ Length of the COP trace on both-feet-standing. ${ }^{*} p<0.05$.

Table 3. Comparison between control- and respiration- sequences for the pre-post difference of the COP change during static standing $(\mathrm{N}=15)$

\begin{tabular}{ccccc}
\hline Standing leg(s)/COP variable & $\begin{array}{c}\mathrm{d} \text { (pre-post) in control } \\
\mathrm{dC}\end{array}$ & $\begin{array}{c}\mathrm{d} \text { (pre-post) in respiration } \\
\mathrm{dR}\end{array}$ & Change & $\mathrm{t}(p)$ \\
\hline Bilateral & & & & \\
Area $\left(\mathrm{mm}^{2}\right)^{\mathrm{a}}$ & $-0.66(55.35)$ & $-37.83(91.60)$ & 37.17 & $1.483(0.160)$ \\
Length $(\mathrm{mm})^{\mathrm{b}}$ & $43.04(117.86)$ & $10.18(63.91)$ & 32.86 & $0.966(0.350)$ \\
Right & & & & $-0.099(0.923)$ \\
Area $\left(\mathrm{mm}^{2}\right)$ & $-30.63(138.39)$ & $-25.79(109.32)$ & -4.84 & $-0.389(0.703)$ \\
Length $(\mathrm{mm})$ & $8.08(41.64)$ & $15.79(43.63)$ & -7.71 & $-1.044(0.314)$ \\
Left & & & & -37.59 \\
Area $\left(\mathrm{mm}^{2}\right)$ & $-33.04(81.93)$ & $4.54(102.12)$ & -25.38 & $-2.156(0.049)^{*}$ \\
Length $(\mathrm{mm})$ & $-7.06(32.79)$ & $18.30(34.29)$ &
\end{tabular}

Values are presented as mean (SD).

COP: center of pressure, $\mathrm{dC}$ : difference between pre- and post-measurements [d (pre-post)] in the control sequence (C), $\mathrm{dR}$ : difference between pre- and post-measurements [d (pre-post)] in the respiration sequence $(\mathrm{R})$.

${ }^{a}$ Area of the eclipse drawn with the short and long axes of the shape of the COP trace. ${ }^{\mathrm{b}}$ Length of the COP trace on both-feet-standing. $* p<0.05$.

showed a greater decrease in the length of the COP after the $\mathrm{R}$ sequence compared to the $\mathrm{C}$ (Table $3, p<0.05$ ). Below the level of statistical significance, the area tended to show no decrease or slight decrease in $\mathrm{R}$ but showed increases in $\mathrm{C}$ during left single-leg standing. There were minor trends showing that COP length and area decreased or increased less after the $\mathrm{R}$ sequence with right single-leg-standing, while those after the $\mathrm{C}$ sequence showed a less decrease or a more increase in COP length and area.

From the HRV measurement, significant pre-post effects in the mean HR was observed only from the experiment sequence; the mean HR was significantly lowered after the R-RGEP (Table 4, $p<0.05$ ). Otherwise, statistically significant differences between the $\mathrm{C}$ sequence and the $\mathrm{R}$ se- 
Table 4. Comparison between pre- and post- measurements of the HRV variable $(\mathrm{N}=15)$

\begin{tabular}{|c|c|c|c|}
\hline HRV variable & Pre & Post & $\mathrm{t}(p)$ \\
\hline \multicolumn{4}{|l|}{$\mathrm{LF}\left(\mathrm{msec}^{2}\right)$} \\
\hline Control & $6.19(0.84)$ & $6.31(0.60)$ & $-1.134(0.276)$ \\
\hline Respiration & $6.11(0.80)$ & $6.33(0.77)$ & $-0.990(0.339)$ \\
\hline \multicolumn{4}{|l|}{$\mathrm{HF}\left(\mathrm{msec}^{2}\right)$} \\
\hline Control & $6.30(1.06)$ & $6.42(1.08)$ & $-0.925(0.370)$ \\
\hline Respiration & $6.47(0.80)$ & $6.44(0.90)$ & $0.122(0.905)$ \\
\hline \multicolumn{4}{|l|}{$\mathrm{LF} / \mathrm{HF}$} \\
\hline Control & $1.13(0.92)$ & $1.11(0.71)$ & $0.137(0.893)$ \\
\hline Respiration & $0.85(0.45)$ & $1.18(0.86)$ & $-1.583(0.136)$ \\
\hline \multicolumn{4}{|c|}{ MEAN HR (beats per minute) } \\
\hline Control & $67.84(6.83)$ & $66.24(7.25)$ & $1.198(0.251)$ \\
\hline Respiration & $68.17(7.13)$ & $63.84(7.01)$ & $2.680(0.018)^{*}$ \\
\hline \multicolumn{4}{|l|}{$\operatorname{SDNN}\left(\mathrm{msec}^{2}\right)$} \\
\hline Control & $53.10(15.88)$ & $57.18(15.79)$ & $-1.735(0.105)$ \\
\hline Respiration & $52.95(14.10)$ & $53.42(16.43)$ & $-0.158(0.877)$ \\
\hline
\end{tabular}

Values are presented as mean (SD).

HRV: heart rate variability, LF: low frequency, HF: high frequency, LF/HF: ratio between low frequency and high frequency, MEAN HR: mean heart rate, SDNN: standard deviation of n-n interval. ${ }^{*} p<0.05$.

Table 5. Comparison between control- and respiration- sequences for the pre-post difference of the HRV variables

$(\mathrm{N}=15)$

\begin{tabular}{lccrr}
\hline \multicolumn{1}{c}{ HRV variable } & $\mathrm{d}$ (pre-post) in control & $\mathrm{d}$ (pre-post) in respiration & Change & $\mathrm{t}(p)$ \\
\hline LF $\left(\mathrm{msec}^{2}\right)$ & \multicolumn{1}{c}{$\mathrm{dR}$} & $-0.21(0.85)$ & $0.09(1.82)$ & $0.380(0.710)$ \\
HF $\left(\mathrm{msec}^{2}\right)$ & $-0.12(0.42)$ & $0.02(0.67)$ & $-0.14(0.75)$ & $-0.729(0.478)$ \\
LF/HF & $-0.12(0.50)$ & $-0.33(0.81)$ & $0.36(1.01)$ & $1.377(0.190)$ \\
MEAN HR (beats per minute) & $0.03(0.79)$ & $4.32(6.25)$ & $-2.73(7.73)$ & $-1.367(0.193)$ \\
SDNN $\left(\mathrm{msec}^{2}\right)$ & $1.60(5.18)$ & $-0.47(11.59)$ & $-3.61(13.75)$ & $-1.016(0.327)$ \\
\hline
\end{tabular}

Values are presented as mean (SD).

HRV: heart rate variability, dC: difference between pre- and post-measurements [d (pre-post)] in the control sequence (C), dR: difference between pre- and post-measurements [d (pre-post)] in the respiration sequence (R), LF: low frequency, HF: high frequency, LF/HF: ratio between low frequency and high frequency, MEAN HR: mean heart rate, SDNN: standard deviation of n-n interval.

quence were not found (Table 5). The trends for the pre-post change were different between the $\mathrm{C}$ and the $\mathrm{R}$, which will be also addressed in the discussion.

\section{Discussion}

This study aimed to find if short-term training in breathing and incorporation of such breathing into an exercise session would lead to an instant gain in stability and balance benefits, and also to see if any observable effect in the ANS would be accompanied in such possible change in balance.

As the length of COP increased or the area of the COP ellipse became larger, it indicated that the sway of the body had increased, and it could be interpreted as a decrease in the ability to maintain balance [24-26]. The results showed that the slow abdominal breathing involved session can more or less beneficial to improving balance, as the significantly positive effect of a decrease in sway length of the COP compared to the control was observed from the single-leg-standing on the non-dominant (left) side (Tables 2, 3). The area of the sway on the left-leg-standing, although it was not to the level of significance as shown in the length of the sway, also showed a tendency to decrease (increase in balance) a small degree in the SAR involved sequence [R-RGEP] while it appeared to increase (decrease in balance) in the control sequence [P-GEP] (Tables 2, 3). Not as prominent as in the left leg standing, such balance-stabilizing effect can be traceable in the case of the right single-leg-standing. With the SAR in- 
volved program [R-RGEP], the ellipse length of the COP displacement had decreased more and the area had increased less than the control program [P-GEP]. The bilateral standing examination did not show any additional balance-improving effect (Tables 2, 3).

The strength of the hip abductors of the non-dominant side was found to be relatively weaker than that of the dominant side in the healthy subjects [27]. For this reason, standing on the non-dominant side may have been more challenging and required more attention to maintain balance. The result of this study showed that SAR brought significant stabilizing effect under the left-side-standing condition and may indicate that breathing exercises can be more helpful in maintaining balance in a more challenging situation. This could be possibly due to the attention-improving effect of breathing exercise [28] since postural control involves significant attention requirement as well as reflex or autonomic control [29]. By the same token, the right single-leg-standing would need a higher level of attention relatively than the easier bilateral standing condition (although the level may be less when compared with left-standing because it is usually the dominant side and has more abductor strength) and it may be the reason that the stabilizing effect after the SAR program was more noticeable in the right single-leg-standing than with bilateral standing.

Considering that the SAR was incorporated to the exercises only after 6 minutes of training and that this short and easy introduction of the SAR still had some supportive effect on balance, it can be indicated that it is worth trying when the time for therapeutic or health-promoting sessions are limited but it is still desirable to obtain additional stabilization or balance improvement. Further studies are required to see if the more distinct effect can be expectable from the longer, repetitive trials. Stephens et al. [30] examined the effect of including 8 weeks extensive breathing exercises on balance in multiple modes of supine, prone, sitting, and with a stretchable belt on, but with no exercise combination or integration. The balance turned out to be improved both in single-leg-standing and in tandem standing after the completion of the programs. On the other hand, Roh [31] examined the effect of the abdominal breathing combined with strengthening exercises for a 6-week period on balance, but the results did not show an improvement in balance compared with the strengthening-only program.

The HRV is defined as beat-to-beat variation in heart rate, and the measurement the HRV parameters can be used to assess autonomic control $[32,33]$. The heart rate is controlled by ANS, and parasympathetic nervous system decreases heart rate. The SDNN means overall variability, and larger variability means higher adaptability to changing stimuli from the environments and higher physical and psychological anti-stress capacity $[33,34]$. The HF is generally considered as representing parasympathetic activity and vagal activation, and is associated with more relaxed state. The LF is reflective of both sympathetic and parasympathetic activities to be associated with baroreflex sensitivity [32,35].

In the study where the relationship between sleep-deprivation and balance in healthy adults, the subjects with deteriorated sleep presented with changes in the HRV parameters (lowered LF, significantly lowered HF, and larger LF/HF) and decreases in balance [36]. This suggests a possibility that the lowered ability in balance may have a relationship with the change in their ANS reactions (toward more sympathetic activation) measured through the HRV. Mikołajec's study [22], as mentioned before, also observed a change in concentration of the sympathetic neurotransmitter of the ANS together with the change in postural stability when the different types of lower extremity strengthening exercise were tried.

The result of our study also showed that the heart rate decreased significantly after the controlled-breathing involved SAR sequence, and, although not to the level of significance, it decreased in the control too. This may indicate that more parasympathetic activation has occurred in both and especially in the SAR involved program and that this ANS modulation could have had an influence on balance. Although more future studies are needed, there is a possibility that the ANS may be involved in balance control in some way or another.

Both breathing and exercises are known to affect the HRV, the cardiovascular ANS marker, in somewhat of a different and varied way $[32,35,37]$. After our SAR combined and integrated exercise session, the directions of the change of the other HRV parameters were increase in LF, almost no change in HF, increase in LF/HF, and a mild increase in SDNN. According to the previous studies, slow breathing or meditation was related to an increase in LF [35,37], which is in line with the same direction of this study. The enhancement of LF of the cardiovascular system was reported to improve baroreflex sensitivity and lower blood pressure in patients with hypertension [37] In the control, which was basically active and resistive exercises with addition of passive exercises, the tendencies of the changes were an increase in $\mathrm{LF}$, increase in HF, almost no change in LF/HF ratio, and an 
increase in SDNN. Somewhat different from the results of our study, active exercises were reported to affect the HRV in the directions of showing a decrease in LF, increase in HF, decrease in LF/HF, and increase in SDNN $[32,35,38]$. However, there are certain types of movement or exercises presented with the varied HRV reaction: for example, eurhythmy movements, moving slowly with meditative imagery, and decreased LF [35]. The inclusion of passive exercises in the control of this study, even though it was included in the intention to make the overall session length the same between the control and the experiment without causing any other additional effect, may actually have affected the HRV in a different direction than active exercises, as seen in the eurhythmy exercise, and this possible influence may have added to the overall change in the HRV.

The new learning and application process for the SAR, can require more alertness and attention, and such process can cause a load of stress, as it can happen in the new learning process [39]. This study involved only a one-time trial of the respiration incorporated intervention. If the trial is repeated over several times, then the initial learning stress will reduce. Further studies are needed to see whether it would bring a more noticeable and clearer effect of balance stabilization or any activation/deactivation of the ANS if controlled respiration intervention is repeated over multiple sessions.

The limitations of this study include having a small number of subjects, although a cross-over design requires a relatively smaller number in terms of statistical analysis. Due to this limitation that renders difficulty in having a clear statistical analysis, the interpretations and considerations about the result of this study should be taken cautiously. Another limitation is the transfer effect, which is intrinsic to a cross-over research design, although it was minimized by wash-out periods.

In conclusion, the slow-abdominal-respiration integrated into an exercise program showed partially positive immediate effect on balance stabilization after a one-time session. The decrease in heart rate after the program indicated possible involvement of the parasympathetic ANS activation, although the extent of the effect was not enough to decide that it was genuinely due to the respiration. Due to the small number of the subjects, the result of this study is suggested to be taken as preliminary, and future research with larger number of subjects and with varied time or repetitions of the respiration training will be needed.

\section{Conflict of Interest}

The authors declared no potential conflicts of interest with respect to the authorship and/or publication of this article.

\section{References}

1. Lin FL, Yeh ML, Lai YH, Lin KC, Yu CJ, Chang JS. Two-month breathing-based walking improves anxiety, depression, dyspnoea and quality of life in chronic obstructive pulmonary disease: a randomised controlled study. J Clin Nurs 2019;28:363240.

2. Fiskin G, Sahin NH. Effect of diaphragmatic breathing exercise on psychological parameters in gestational diabetes: a randomised controlled trial. Eur J Integr Med 2018;23:50-6.

3. Kamath A, Urval RP, Shenoy AK. Effect of alternate nostril breathing exercise on experimentally induced anxiety in healthy volunteers using the simulated public speaking model: a randomized controlled pilot study. Biomed Res Int 2017;2017:2450670.

4. Dinesh T, Dinesh Kumar E, Rajajeyakumar M, Charumathi V. Effect of short-term breathing exercise training on perceived stress and Stroop effect in chronic smartphone users. Int Arch Integr Med 2018;5:1-7.

5. Srinivasan B, Rajkumar D. Effects of slow breathing on blood pressure and end tidal carbon dioxide in hypertension: randomised controlled trial. J Clin Diagn Res 2019;13:1-3.

6. Jafari H, Courtois I, Van den Bergh O, Vlaeyen JWS, Van Diest I. Pain and respiration: a systematic review. Pain 2017;158:9951006.

7. Garrido M, Castaño MY, Biehl-Printes C, Gomez MA, Branco JC, Tomas-Carus P, et al. Effects of a respiratory functional training program on pain and sleep quality in patients with fibromyalgia: a pilot study. Complement Ther Clin Pract 2017;28: $116-21$.

8. Goso Y, Asanoi H, Ishise H, Kameyama T, Hirai T, Nozawa T, et al. Respiratory modulation of muscle sympathetic nerve activity in patients with chronic heart failure. Circulation 2001;104:41823.

9. Yong MS, Lee YS, Lee HY. Effects of breathing exercises on resting metabolic rate and maximal oxygen uptake. J Phys Ther Sci 2018;30:1173-5.

10. Wang SZ, Li S, Xu XY, Lin GP, Shao L, Zhao Y, et al. Effect of slow abdominal breathing combined with biofeedback on blood pressure and heart rate variability in prehypertension. J Altern Complement Med 2010;16:1039-45.

11. Beng TS, Jie HW, Yan LH, Ni CX, Capelle DP, Yee A, et al. The effect of 20-minute mindful breathing on the perception of suffering and changes in Bispectral Index Score in palliative care patients: a randomized controlled study. Am J Hosp Palliat Care 2019;36:478-84.

12. Alaparthi GK, Augustine AJ, Anand R, Mahale A. Comparison of diaphragmatic breathing exercise, volume and flow incentive spirometry, on diaphragm excursion and pulmonary function in patients undergoing laparoscopic surgery: a randomized controlled trial. Minim Invasive Surg 2016;2016:1967532. 
13. Kang JI, Jeong DK, Choi H. The effects of breathing exercise types on respiratory muscle activity and body function in patients with mild chronic obstructive pulmonary disease. J Phys Ther Sci 2016;28:500-5.

14. Yokogawa M, Kurebayashi T, Ichimura T, Nishino M, Miaki H, Nakagawa T. Comparison of two instructions for deep breathing exercise: non-specific and diaphragmatic breathing. J Phys Ther Sci 2018;30:614-8.

15. Hodges PW, Gandevia SC. Changes in intra-abdominal pressure during postural and respiratory activation of the human diaphragm. J Appl Physiol (1985) 2000;89:967-76.

16. Tayashiki K, Maeo S, Usui S, Miyamoto N, Kanehisa H. Effect of abdominal bracing training on strength and power of trunk and lower limb muscles. European Journal of Applied Physiology 2016;116:1703-13.

17. Kim JG, Kim JH, Do KS, Kim J. Effect of light touch on body sway during a stable posture with blocked visual information. Phys Ther Rehabil Sci 2016;5:138-42.

18. Park J, Chung Y. The effects of an additional weight aqatic exercises program on balance and lower extremity strength in persons with stroke: randomized controlled study. Phys Ther Rehabil Sci 2018;7:6-12.

19. Asakawa Y, Lee MM, Song CH. The effect of whole body vibration training on postural sway in patients with spinal cord injury: a pilot study. Phys Ther Rehabil Sci 2013;2:70-4.

20. Park YH, Lee CH, Kim HJ. A pilot study of augmented reality-based postural control training in stroke rehabilitation. Phys Ther Rehabil Sci 2014;3:13-9.

21. Modesti PA, Ferrari A, Bazzini C, Boddi M. Time sequence of autonomic changes induced by daily slow-breathing sessions. Clin Auton Res 2015;25:95-104.

22. Kazimierz M, Adam M, Matgorzata C, Józef L, Artur G, Adam $Z$. The influence of strength exercises of the lower limbs on postural stability: a possible role of the autonomic nervous system. Isokinet Exerc Sci 2017;25:79-89.

23. Pahra D, Sharma N, Ghai S, Hajela A, Bhansali S, Bhansali A. Impact of post-meal and one-time daily exercise in patient with type 2 diabetes mellitus: a randomized crossover study. Diabetol Metab Syndr 2017;9:64.

24. Thompson LA, Badache M, Cale S, Behera L, Zhang N. Balance performance as observed by center-of-pressure parameter characteristics in male soccer athletes and non-athletes. Sports (Basel) 2017;5:E86.

25. Kim GH, Tak JY, Lim HY, Jeong HS, Woo YK. Effects of various sensory stimulation on surface area and velocity of center of pressure during one leg standing in healthy adults. Phys Ther Korea 2015;22:41-9.
26. Demura S, Uchiyama M. Influence of anaerobic and aerobic exercises on the center of pressure during an upright posture. J Exerc Sci Fit 2009;7:39-47.

27. Jacobs C, Uhl TL, Seeley M, Sterling W, Goodrich L. Strength and fatigability of the dominant and nondominant hip abductors. J Athl Train 2005;40:203-6.

28. Telles S, Gupta RK, Gandharva K, Vishwakarma B, Kala N, Balkrishna A. Immediate effect of a yoga breathing practice on attention and anxiety in pre-teen children. Children (Basel) 2019; 6:E84.

29. Woollacott M, Shumway-Cook A. Attention and the control of posture and gait: a review of an emerging area of research. Gait Posture 2002;16:1-14.

30. Stephens RJ, Haas M, Moore WL 3rd, Emmil JR, Sipress JA, Williams A. Effects of diaphragmatic breathing patterns on balance: a preliminary clinical trial. J Manipulative Physiol Ther 2017;40:169-75.

31. Roh $\mathrm{H}$. The effect of abdominal breathing with muscle strength exercise on balance and strength. Neurotherapy 2018;22:33-8.

32. Hsu CY, Hsieh PL, Hsiao SF, Chien MY. Effects of exercise training on autonomic function in chronic heart failure: systematic review. Biomed Res Int 2015;2015:591708.

33. da Silva VP, de Oliveira NA, Silveira H, Mello RG, Deslandes AC. Heart rate variability indexes as a marker of chronic adaptation in athletes: a systematic review. Ann Noninvasive Electrocardiol 2015;20:108-18.

34. Kim JS. The effects of breathing exercises on the change of autonomic nervous system activity in female adults. J Korean Assoc Phys Educ Sport Girls Women 2016;30:295-309.

35. Edelhäuser F, Minnerop A, Trapp B, Büssing A, Cysarz D. Eurythmy therapy increases specific oscillations of heart rate variability. BMC Complement Altern Med 2015;15:167.

36. Montesinos L, Castaldo R, Cappuccio FP, Pecchia L. Day-to-day variations in sleep quality affect standing balance in healthy adults. Sci Rep 2018;8:17504.

37. Joseph CN, Porta C, Casucci G, Casiraghi N, Maffeis M, Rossi $\mathrm{M}$, et al. Slow breathing improves arterial baroreflex sensitivity and decreases blood pressure in essential hypertension. Hypertension 2005;46:714-8.

38. Ricca-Mallada R, Migliaro ER, Piskorski J, Guzik P. Exercise training slows down heart rate and improves deceleration and acceleration capacity in patients with heart failure. J Electrocardiol 2012;45:214-9.

39. Music S, Rossell SL. Effects of stress on learning and memory. In: Fink G, editor. Stress: concepts, cognition, emotion, and behavior. Elsevier Inc.; 2016. p. 153-60. 